\title{
¿DISOLUCIÓN O RECONCILIACIÓN \\ TRANSFORMADORA DE LA ESTÉTICA \\ EN HEGEL? UNA RESPUESTA
}

\section{DISSOLUTION OR TRANSFORMING RECONCILIATION IN HEGEL'S AESTHETICS? A RESPONSE}

\author{
Ricardo Mejía Fernández ${ }^{1}$ \\ Université París 1 Panthéon-Sorbonne
}

Recibido: 12/01/2016

Aceptado: 13/06/2017

Resumen: En este artículo intentamos responder nuevamente a la tradicional pregunta de si la estética de Hegel ha acabado por ser disuelta en un discurso sobre el arte o, si por el contrario, se trata de un tipo de reconciliación transformadora entre arte y filosofía, es decir, del arte en la filosofía y de la filosofía en el arte. Primero analizamos la ambición de Hegel de convertir la estética en una ciencia, para luego, como sucedía en la política, examinar qué tipo de reconciliación transformadora es viable en el pensamiento del alemán tanto sobre lo bello natural como lo bello artístico.

Palabras-clave: Hegel; estética; arte; filosofía; reconciliación.

\begin{abstract}
In this article, we try to answer again the traditional question of whether Hegel's aesthetic has finally been dissolved in a discourse about art, or if, on the contrary, it is a type of transformative reconciliation between art and philosophy, that is, of art in philosophy and of philosophy in art. First, we analyze Hegel's ambition to turn aesthetics into a science, and then, as in politics, we proceed to examine what kind of transformative reconciliation is or not viable in the German's thinking about both the natural and the artistic quality of beauty.
\end{abstract}

Abstract: Hegel; aesthetics; art; philosophy; reconciliation.

1. (ricardomejia@usal.es) Actualmente es "Profesor Invitado" (Professeur Invité) en la Universidad de la Sorbona, Francia. Ha sido "Investigador" (Chercheur Visiteur) en la Universidad de Lovaina, Bélgica, y es profesor contratado en el CESAG de Palma de Mallorca, España. Además de ser licenciado en Filosofía por la Universidad Pontificia de Salamanca, es máster y doctorando en Lógica y Filosofía de la Ciencia, mención europea, en la Universidad de Salamanca. Cuenta con diversas publicaciones y participaciones en congresos nacionales e internacionales. 


\section{Introducción: La estética como ciencia}

En este artículo me pregunto e intento responder si, en Hegel, la estética se disuelve en una suerte de narrativa reflexiva del arte, o si, por contra, se reconcilia y transforma en su vinculación con el mismo. También si el arte desaparece del todo en su filosofía de la belleza. Hay autores como Jean-Luc Nancy que constatan que no hay propiamente estética si se conserva cualquier discurso centrado per se en el arte: «el arte debe disolverse y relevar su propio fin en el elemento del pensamiento» ${ }^{2}$. Como ilustra al respecto Louis Ucciani, «podemos esquematizar e ir más lejos hasta enunciar que, para que aparezca un discurso [estético] sobre el arte, hace falta que el arte haya desaparecido» ${ }^{3}$. Raymond Bayer, en su Historia de la estética, mantiene que «el arte, según había notado Kant, es demasiado frívolo para prestarse a una investigación del espíritu; no es más que una distracción; ...una mera diversión; nuestra condición humana tiene otras cuestiones más esenciales que plantearse» ${ }^{4}$.

Pero, ¿tan prescindible es el arte en una estética que merezca llevar este nombre? ¿Muere la estética a manos del discurso sobre el arte en Hegel y a la inversa? Sus mejores comentadores, como por ejemplo Ernst Bloch, señalan que "la estética profesada por Hegel no es una estética formal; sino de contenido; y es ahora cuando renace el sentido para comprender este algo materialı $\aleph^{5}$. Pero, más que hacer un trabajo sobre los comentarios a un autor, aquí me sumerjo en el propio autor, en especial en sus cursos sobre estética correspondientes a su etapa de madurez; aunque cuando sea preciso me detendré también en su curso de verano de 1826 recogidos por Friedrich von Kehler ${ }^{7}$. No me son suficientes las glosas

2. Nancy, J-L.: Les muses. Paris: Galilée, 1994, p. 24.

3. Ucciani, L.: "Schopenhauer ou l'esthétique comme instance de renversement" en Philosophique 7, 2004, p. 29.

4. Bayer, R.: Historia de la estética, México D.F.: Fondo de Cultura Económica, 1980, p. 319.

5. Bloch, E.: Sujeto-Objeto. El pensamiento de Hegel. Traducción de Wenceslao Roces, José María Ripalda, Guillermo Hirata y Justo Pérez del Corral. México, D.F.: Fondo de Cultura Económica, 1963 p. 257.

6. De los que tenemos constancia de manera póstuma en las Lecciones de estética que impartió en la Universidad de Berlín (1821-1829) y que conocemos gracias a sus alumnos Gustav Hotto y Von Ascheberg. Como aquí citamos una traducción española y al no haber una única forma de referenciar al autor, si se desea compararlo con el texto alemán remitimos a Hegel, G.W.F.: Vorlesungen über die Ästhetik I. Gesammelte Werke. Vol. 13. Frankfurt am Main: Surhkamp, 1986. De todas formas, durante todo el texto en español acompañaremos los términos y expresiones en alemán más pertinentes a nuestro comentario.

7. Afortunadamente contamos en España con la edición de estos cursos de verano del pensador alemán: Hegel, G.W.F.: Filosofía del arte o Estética. Apuntes de Friedrich Carl Hermann

Thémata. Revista de Filosofía №56 (2017) pp.: 13-40. 


\section{¿Disolución o reconciliación transformadora \\ de la estética en Hegel? Una respuesta}

a Hegel sin leer antes a Hegel mismo, de modo que mi artículo se propone ser una lectura renovada de su propio pensamiento. Para el filósofo y en severa distancia de un Kant para quien "se puede discutir sobre lo bello sin convertirlo en ciencia» ${ }^{8}$, la estética (Ästhetik) es ciertamente una ciencia (Wissenschaft), y, todavía más, "designa más propiamente a la ciencia del sentido [Wissenschaft des Sinnes] de la sensación [Empfindens] ${ }^{9}$. Pero el filósofo ofrecerá su propia visión de la estética a diferencia de la recibida de sus predecesores. En los autores anteriores a él, como en la Estética de Alexander Baumgarten (1750), la facultad sensorial es la única que daba soporte antropológico al discurso sobre lo bello: la sensibilidad es de donde partía, permanecía y ahondaba dicho discurso.

Esto es en parte cierto a ojos de Hegel pero solamente en un primer momento de la experiencia estética y sin persistir en este primer hito exterior de la misma. Desde su etapa de Jena, en la Fenomenología del espíritu (1807), la ciencia coincidía con una filosofía en la que «es esencialmente lo universal lo que encierra lo particular ${ }^{10}$. Ante todo, y ya en su etapa de madurez en Berlín, el filósofo de Stuttgart alerta a sus pupilos que la ciencia estética no se tiene que confundir con una versión objetivista-externista ni sensualista de la misma, sino justamente "como algo que había de llegar a ser una disciplina filosófica [philosophische Disziplin]» ${ }^{11}$. Esto condujo a que Hegel denunciase que, en su coetánea Alemania, desafortunadamente, la estética no había sido pertinentemente fundamentada racionalmente, como es propio de la filosofía; por lo cual estaba siendo confundida solamente con lo objetivo externo de las sensaciones, esto es, con lo que éstas "estaban destinadas a producir»" ${ }^{12}$.

Por este motivo, el pensador alemán entiende la estética de una manera racionalmente más decisoria, a diferencia de lo que en su época se llamaba "calística [Kallistik]», la cual «no considera lo bello en general [das Schöne überhaupt] sino solamente lo bello del arte [das Schöne der Kunst]» ${ }^{13}$. A Hegel le interesa lo bello del arte pero no se conforma con ello ni con una ciencia acumulativa de conocimientos sobre lo bello. En Jena ya

Victor von Kehler. Madrid: Abada Editores / Universidad Autónoma de Madrid Ediciones, 2006. Esta edición, traducida al español por Domingo Hernández Sánchez, está basada en la edición alemana a cargo de Gethmann-Siefert y Collenberg-Plotnikov.

8. Bayer, R.: op. cit., p. 319.

9. Hegel, G.W.F.: Lecciones de estética. Volumen I. Traducción y prólogo de Raúl Gabás. Barcelona: Ediciones Península, 1989, p. 9.

10. Hegel, G.W.F.: Fenomenología del espíritu. Edición bilingüe de Antonio Gómez Ramos. Madrid: Abada, 2010, p. 55.

11. Hegel, G.W.F.: Lecciones, cit., p. 9.

12. Ídem.

13..Ídem.

Thémata. Revista de Filosofía N56 (2017) pp.: 13-40. 
pensaba que, a diferencia de su propia noción de ciencia, hay quienes hacen de ella una provisión de saberes y, según no confiesa, "semejante agregado de conocimientos [Aggregate von Kentnissen]... no lleva legítimamente el nombre de ciencia»" ${ }^{14}$. Y es que en lo que Hegel denomina la "verdadera ciencia de lo bello [wahre Wissenschaft des Schönen]... no se trata de ver solamente qué han hecho otros con acierto o desacierto, o de aprender simplemente de ellos» ${ }^{15}$. Lo bello de las obras de arte no extingue el campo de la ciencia estética. Más bien lo bello del arte requiere de una disciplina que se ocupe filosóficamente de lo bello en su máxima universalidad, lo cual el arte, a su vez, expresa materialmente en sus rasgos sensibles.

Sin despreciar lo obrado por los artistas, el alemán buscaba «formas de tratar científicamente la belleza y el arte» ${ }^{16}$, lamentando, incluso en contra a veces de su misma generalidad, que «no tenemos todavía ante nosotros el concepto de lo bello en forma científica» ${ }^{17}$. Es indudable que, para el autor, la cuestión de la cientificidad de la estética es inexcusable. Sin embargo, en Hegel, la independencia de la estética con respecto del arte no es absoluta ni tampoco deseada por él debido a que, aunque a veces es tenido raramente por un idealista de tipo platónico, su pensamiento precisa de la materia. Es, por ello, que entre la estética y la filosofía del arte no hay bregas imposibles de reconciliar, de suerte que Hegel admite textualmente que «la expresión genuina para nuestra ciencia es la de filosofía del arte y, más exactamente, filosofía del arte bello [Philosophie der Schönen Kunst $\gg_{\aleph^{18}}$. ¿Es esto una disolución de la estética para convertirla escuetamente en conocimiento erudito del arte?

Iré respondiendo a esto en mi artículo. No obstante y por el momento, no quiero desembocar en malentendidos: con "filosofía del arte bello» lo que le interesa a Hegel no es el arte por el arte y nada más, sino, primo facie, su filosofía; en este caso entendida como la reflexión sobre la universalidad de lo bello en toda obra de arte. La calística se reducía a tratar la belleza de las obras artísticas solamente desde sus características materiales y sensibles, sin notar su relación con el espíritu creador que la ingenia y lleva a término. Por el contrario, la estética que busca el alemán relaciona esa belleza sensible con la belleza inteligible, formando así una totalidad de relaciones determinadas. Pero hablar de relaciones no es hablar de ruptura sino, al

14. Hegel, G.W.F.: Fenomenología, cit., p. 9.

15. Hegel, G.W.F.: Lecciones, cit., p. 85.

16. Ibidem, p. 19.

17. Ibidem, p. 29.

18. Ibidem, p. 9.

Thémata. Revista de Filosofía $\mathrm{N}^{\circ} 56$ (2017) pp.: 13-40. 


\section{¿Disolución o reconciliación transformadora \\ de la estética en Hegel? Una respuesta}

igual que en la política, de reconciliación. La estética universal es el aliado necesario del arte y lo incorpora a sí, a la vez que lo transforma.

\section{Una estética de la reconciliación transformadora}

Como señala Paredes Martín a propósito de la política del autor, Hegel apuesta por una "visión racional reconciliadora», en la cual "se refiere tanto a un proceso -el proceso de superar los conflictos, las divisiones y la alienación- como al resultado del mismo, que logra la reunificación de los procesos antagónicos» ${ }^{19}$. Años antes, Denis L. Rosenfield, en su Introducción al pensamiento político de Hegel, daba cuenta de dicha reconciliación a un nivel más palmario, esto, es en la configuración histórica del Estado, al igual que en la estética -quisiera apreciar- la idea se plasma en la obra de arte. En efecto, «es en el Estado donde desaparecen las oposiciones entre gobierno y estados sociales (Stände) y entre gobierno y provincias (Länder), puesto que a partir de entonces toda la vida política se desenvolverá en su interior mediante una esfera pública común donde los intereses particulares se chocan y se contradicen, pero no alteran la articulación del todo» ${ }^{20}$.

Por ello y como sucede en la teoría del Estado, dicha reconciliación no es el amistarse estático de aspectos en pugna sino sobre todo una transformación porque la estética hegeliana busca dar razón de cómo, a partir de la nuda materia y sin abandonarla jamás, el espíritu es capaz de otorgarle belleza, y, de este modo, elevarla a la universalidad. En este proceso, "es importante la transformación que se opera, ya que reconciliarse con algo no significa dejar que las cosas queden como están, ni tampoco atenerse a lo que hay, sino establecer relaciones nuevas que posibiliten una unidad superior, más compleja y más consistente que la unidad destruida ${ }^{21}$. Es esa transformación creativa del espíritu, que el alemán asocia al arte, de la que la estética ha de dar cuenta racional y, por ende, realizarlo desde la óptica universal. Pero queremos avisar que esto eso no es un idealismo platónico.

Notemos, por ahora, lo siguiente: a Hegel siempre le importa lo bello en general de la obra de arte, nunca solamente lo bello en sí mismo como si se tratara de un eidos puro fuera de las producciones del hombre

19. Paredes Martín, M.C.: «Hegel: el héroe político» en Bonete Perales, E. (edit.): La política desde la ética. Barcelona: Proyecto A Ediciones, p. 128.

20. Rosenfield, D.L.: Introducción al pensamiento político de Hegel. Buenos Aires: Editorial Almagesto, 1995, p. 23.

21. Paredes Martín, M.C.: op. cit., p. 128.

Thémata. Revista de Filosofía N56 (2017) pp.: 13-40. 
ya que, de lo contrario, convertiríamos a Hegel es un pupilo más de la Academia de Atenas fundada por Platón. Tampoco le obsesiona al filósofo lo bello solamente de la obra de arte o la sensación privada ante lo bello. Esto viene avalado en que hay diferencias entre la lógica hegeliana, como ciencia de la idea en sí misma, y la estética, como ciencia o disciplina racional de la belleza artística. Para el alemán debe existir una reconciliación transformadora entre la idea y la producción artística ya que lo bello no se puede gozar sin las dos. Así lo certifica Holzermayr Rosenfield: «Poniendo al desnudo el movimiento intrínseco con todo momento de la actividad artística, la Estética retoma su articulación propia en la Ciencia de la lógica» ${ }^{22}$. En este sistema, «la lógica no es realidad primera, ni tampoco estudio de conocimiento en tanto que instrumento previo a su ejercicio, sino que es mediación del contenido en relación consigo mismo» ${ }^{23}$. Empero, el filósofo constataba un menoscabo de la cientificidad y unicidad de la estética ya que «nos encontramos de nuevo con dos formas opuestas, y parece que cada una excluye a la otra y no nos permite llegar a ningún resultado verdadero [wahren Resultat] $»^{24}$. Estas dos formas, que el alemán define y ejemplifica con extrema precisión, son las siguientes:

1) La primera posición es lo que Hegel llama «ciencia del arte» (Wissenschaft der Kunst), la cual "se esfuerza por llegar a las obras existentes [wirklichen Werken] como rodeándolas desde fuera [außen herum], las ordena en la historia del arte, hace consideraciones sobre las obras de arte conocidas, o formula teorías que han de proporcionar puntos de vista generales para su enjuiciamiento o para la producción científica de las mismas» ${ }^{25}$. En esta versión, lo que interesa es la realidad efectiva (Wirklichkeit) de las obras de arte, desde el exterior, en cuanto pueden ser ordenadas científicamente en sus cualidades sensibles de manera histórica, teórica y técnica. Se trata, pues, de la estética del exterior y solamente es valiosa científicamente en tanto en cuanto es portadora de datos objetivos externos a racionalizar. Aquí entran tanto la historia del arte convencional como la teoría del arte, así como las técnicas de tratamiento y conservación de las obras artísticas. Este tipo de hacer estética

22. Holzermayr Rosenfield, R.: "Une faille dans l'Esthétique de Hegel: À propos du silence sur le roman de Goethe et la lyrique de Hölderlin" en Revue Canadiénne de Littérature Comparée 17, (1-2), 1990, p. 1.

23. Ídem.

24. Hegel, G.W.F.: Lecciones, cit., p. 19.

25. Ídem.

Thémata. Revista de Filosofía N56 (2017) pp.: 13-40. 
«parte de lo particular y existente» ${ }^{26}$ y «toma como punto de partida lo empírico» ${ }^{27}$. Sin embargo, este "material histórico concreto... no es el cometido de la filosofía" debido a que, al no ser más que «erudición [Gelehrsamkeit]»" 28 , «no tiene por objeto el auténtico teorizar» ${ }^{29}$. Y es que la filosofía tiene como objetivo alcanzar un conocimiento universal que va más allá y es anterior a la acumulación erudita de conocimientos. La estética no puede contentarse con saber mucho sobre obras de arte, sin saber nada de lo bello desde el enfoque filosófico universal.

2) La otra versión, contraria a la que acabo de presentar, es una estética pura de corte fichteano, basada en "la idea lógica de lo bello [die logische Idee des Schönen] $\aleph^{30}$ y que asienta su cientificidad precisamente en su puridad metodológica para tratar lo bello. Esta «ciencia desarrolla autónomamente desde sí misma la idea de lo bello, con lo cual habla solamente de aspectos generales, produce una filosofía abstracta de lo bello [eine abstrakte Philosophie des Schönen], pero sin acertar con la obra de arte en su peculiaridad $»^{31}$. A Hegel le displace esta estética debido a su exceso abstractivo ya que es una "reflexión puramente teórica, que se esfuerza por conocer lo bello como tal desde sí mismo y por fundamentar su idea $^{32}$. El filósofo achaca este tipo insatisfactorio de hacer estética a Platón, para quien no importaban «los objetos en su particularidad, sino en su universalidad, en su especie, en su ser.... ${ }^{33}$. Se equivocan crasamente quienes han interpretado el pensamiento hegeliano como un abstraccionismo ya que el filósofo confiesa, sabiendo que hay que partir siempre de una noción inteligible de lo bello, que no basta con conocer «lo bello según su esencia y concepto» puesto que "puede convertirse a su vez en una metafísica abstracta [zu einer abstrakten

26. Ibidem, p. 26.

27. Ibídem, p. 20.

28. Ibidem, p. 25.

29. Ibidem, p. 26.

30. Ídem.

31. Ibidem, p. 20.

32. Ibidem, p. 26.

33. Ídem.

Thémata. Revista de Filosofía №56 (2017) pp.: 13-40. 
Metaphysik werden] $\rangle^{34}$. El idealismo hegeliano, como se puede observar, difiere del idealismo platónico. Para el alemán, "resulta insuficiente la abstracción platónica», de modo que tenemos «que esforzarnos por una comprensión más profunda y concreta.... $»^{35}$.

¿Puede haber alguna vía intermedia entre 1) y 2)? En la versión de Hegel, el enfrentamiento entre las dos posiciones anteriores es un signo de atraso intelectual y de no entender bien lo que tenemos entre manos. Debemos apostar sin vacilar por la reconciliación. La filosofía inculca que ambas posiciones se necesitan ya que, si uno se quedamos nada más con la primera, pierde el porqué absoluto del cómo más concreto del arte. Si, por el contrario, uno se conforma con la segunda, sería muy cuestionable que supiese efectivamente qué es lo bello porque, pese a las múltiples divagaciones mentales que haga sobre lo bello en sí mismo, le faltarían los ejemplos y conocimientos artísticos -teóricos y técnicos- para mostrarlo científicamente. Como escribe el filósofo de Stuttgart, «lo externo no tiene una validez inmediata para nosotros, sino que suponemos por detrás un interior [ein Inneres], una significación [eine Bedeutung], gracias a la cual queda espiritualizada [begeistet wird] la manifestación exterior [die Außenerscheinung] ${ }^{36}$. Es este interior extrovertido el que opera la reconciliación y transformación que aquí defendemos, ya que sería inhábil sin lo externo.

De esto, pues, se ocupa la estética de Hegel: de lo externo bello del arte desde el ángulo del espíritu, pero acentuando el espíritu transformador que es el que da de sí dicha significación espiritual y la reconcilia consigo. La estética hegeliana se caracteriza como una estética del interior pero, valga la paradoja, de un interior volcado al exterior, que, retornando a sí, transforma la esencia bella de lo exterior que así lo merite. Es decir, en «una obra de arte comenzamos por lo que se nos presenta inmediatamente [unmitterbal präsentiert], y sólo entonces preguntamos cuál es allí la significación o el contenido» ${ }^{37}$, entendiendo el contenido en el sentido de $l o$ que es contenido dentro (inhalt). En el pasado, en sus tareas académicas en Jena, que lo que le preocupaba no era «lo externo inesencial [unwesentliche Äußere]» sino lo «lo interno esencial [wesentliche Innere], es el ser-dentrode-sí [Insichsein] de la individualidad $\aleph^{38}$; si bien en su nueva estética esta individualidad será superada por la razón universal en el arte. Hay un

34. Ídem.

35. Ídem.

36. Ibidem, p. 24.

37. Ídem.

38. Hegel, G.W.F.: Fenomenología, cit., p. 397.

Thémata. Revista de Filosofía ํ56 (2017) pp.: 13-40. 


\section{¿Disolución o reconciliación transformadora \\ de la estética en Hegel? Una respuesta}

progreso a la vez que una continuidad entre la fenomenología y la estética en Hegel, sin embargo no se inmiscuye en un análisis fenomenológico más exhaustivo de la experiencia individual de lo bello, como, por ejemplo, encontramos en Edmund Husserl. Según el de Stuttgart, el interior se vuelca al afuera pero en la medida es que es esencialmente interior.

La estética hegeliana puede calificarse, por ello y como acabo de comprobar, de presentista y racionalista en una relación dialéctica adentro-afuera. Es presentista, porque la experiencia de lo bello acontece en el ahora inmediato de la sensación aunque sin anquilosarse ahí. Por ello también es racionalista, porque lo sensitivo inmediato precisa de la actividad transformadora del espíritu en reconocer ese contenido interno bello y reconciliarlo consigo universalmente. En el pensador alemán, el racionalismo es más fuerte que el presentismo pero no es contradictorio con él pues, en la experiencia de lo bello, reina la distancia «por cuanto lo exterior aleja de sí [von sich hinweg] y señala hacia lo interior» ${ }^{39}$. La experiencia estética se disfruta en la lejanía espiritual, o, para ser más literales con la lengua alemana, en la ida (Hinweg) de lo exterior. Pero esto no supone la lejanía de la secesión sino, como vengo recalcando en lenguaje dialéctico, una lejanía relacional que tiende a la reconciliación: lo bello externo, en su contenido, se disfruta internamente en la medida en que hay afuera y hay adentro. De esta manera, y como bien lo resume Hegel, «los elementos de lo bello son un interior [ein Inneres], un contenido [einen Inhalt], y un exterior [ein Äußeres], en el cual queda significado el contenido» ${ }^{40}$.

La estética del alemán, pues, reconcilia estos elementos en el arte, toda vez que los transforma en el quicio del espíritu. Tal y como leemos en su obra, entre las dos posturas enfrentadas anteriormente descritas, lo bello «debe contener en sí como mediados los dos extremos indicados, uniendo la universalidad metafísica [metaphysische Allgemeinheit] con la determinación de la particularidad real [Bestimmtheit realer Besonderhei$t] »^{41}$. El concepto de lo bello será, de este modo, «aprehendido en sí y para sí en su verdad $»^{42}$. El siglo XIX, en el que vivió nuestro autor, fue una época en la que despuntó el historicismo pero a la vez el ideal del progreso, es decir, los detalles más ínfimos del saber con las proyecciones más generales de la razón. Hegel, que era partidario del arte romántico, abogaba por una estética en la que no fuese un imposible reconciliar erudición y reflexión, «por razón del mencionado progreso de la receptividad espiritual

39. Hegel, G.W.F.: Lecciones, cit., p. 25.

40. Ídem.

41. Ibídem, p. 26.

42. Ídem.

Thémata. Revista de Filosofía №56 (2017) pp.: 13-40. 


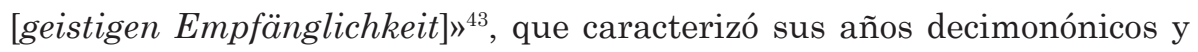
su propio pensamiento. Esta última expresión es muy ilustradora para nuestro artículo.

Así pues, esta receptividad (Empfänglichkeit) expresa mucho del espíritu de Hegel porque, con ella, se indica que el espíritu es capaz de recibir lo que los dualistas (o monistas de lo suyo) anteriores, los de la ciencia del arte y los de la lógica de lo bello oponían entre sí: el espíritu no sólo asume lo concreto bello en su efectividad particular sino que, sin este mismo espíritu que conceptualiza reconciliando y transformando, no habría como tal ninguna cualidad bella universal ni en la naturaleza ni en el arte, como se verá en los próximos dos puntos. No cabe duda que el espíritu de Hegel se subleva contra el pensamiento único y unilateral, transformando la esterilidad del concepto parcial de lo bello de externistas e internistas en una fecundidad bella universal a través de sus momentos particulares y sin salirse de su mismo despliegue espiritual total:

Pues, por una parte, [el concepto de lo bello] es fértil por sí mismo, frente a la esterilidad [Sterilität] de la reflexión unilateral, puesto que en virtud de su propio concepto ha de desarrollarse hacia una totalidad de determinaciones [Totalität von Bestimmungen], y tanto él como su despliegue [seine Auseinandersetzung] contienen la necesidad [Notwendigkeit] de sus momentos particulares y del progreso y transición entre éstos. Y, por otra parte, los momentos particulares, hacia los cuales se progresa, llevan en sí la universalidad y esencia del concepto, que aparece en ellos como en sus propias particularidades ${ }^{44}$.

\section{Lo bello natural: la deficiencia de la naturaleza}

Al delimitar su estética como filosofía del arte bello, el de Stuttgart avisa al lector que mediante «esta expresión excluimos inmediatamente lo bello natural [Naturschöne] $\aleph^{45}$. Lo bello natural es la cualidad estética que atribuimos a los seres de la naturaleza, como cuando, por ejemplo, decimos «cielo hermoso, bellos arroyos, bellas flores»" ${ }^{46}$ etc. Esta exclusión de lo bello natural podría ser considerada por el lector como una estrechez de Hegel porque es obvio que no le interesa tanto lo bello en sí únicamente, como

43. Ibidem, p. 25.

44. Ibidem, p. 26 y p. 27 respectivamente.

45. Ibidem, p. 9.

46. Ídem.

Thémata. Revista de Filosofía №56 (2017) pp.: 13-40. 
sucedía con la idea en puridad de su peculiar lógica, sino principalmente lo bello del arte. Esto, aunque no lo captemos a simple vista, es cuanto menos consecuente con el sistema hegeliano, porque en la espiral dialéctica del espíritu, el arte supone una sublimación, ya conscientemente humana, de los estadios naturales inferiores en que el espíritu va desplegándose.

La filosofía de la naturaleza corresponde a un estadio todavía no alta y cualitativamente conformado por el espíritu pues le falta una relación de mayor creatividad para con él. Por eso, Hegel llama nuestra atención sosteniendo la «deficiencia del bello natural [Mangelhaftigkeit des Naturschöne]» ya que «la naturaleza es necesariamente imperfecta en su belleza ${ }^{47}$. El espíritu que crea lo bello artístico es perfecto y necesario. Lo bello del arte, por su parte, es mucho más perfecto, en cuanto adquiere una mayor cualidad espiritual en la materia en comparación con los solos productos de la naturaleza, la cual corresponde a formas menos desarrolladas del espíritu, como son los fenómenos mecánicos, físicos o biológicos. El arte, la religión y la filosofía corresponden al espíritu absoluto en el que la idea pasa de ser de simple exterioridad en-sí, como es típico de la naturaleza, al para-sí absoluto del espíritu. Pero Hegel no opone en su estética la filosofía de la naturaleza a la filosofía del espíritu sino que, más bien, procede «situando lo bello natural junto a [neben] lo bello artístico» ${ }^{48}$. Con el adverbio en alemán «junto a [neben]» no hemos de concebir lo que enseña Hegel como dos substancias una junto a la otra sino como dos aspectos, cualitativamente diversos, del mismo dinamismo, también diverso, del espíritu. No podemos sino reconocer que lo bello es compartido tanto por seres naturales como por los artefactuales, ambos provenientes del mismo desarrollo del espíritu, aunque no en el mismo estadio de realización creativa, según si el espíritu se encuentra en su forma objetiva, subjetiva o absoluta; ni tampoco en el mismo nivel cualitativo. Si tuviésemos que comparar la «cualidad de la belleza [Qualität Schönheit]» ${ }^{49}$ que distingue a las cosas y fenómenos, así como a las obras de arte, veríamos que el grado de implicación y cualidad espiritual es mayor en lo artístico:

... afirmamos ya de entrada que la belleza artística es superior a la naturaleza. En efecto, lo bello del arte es la belleza nacida y renacida del espiritu. En la misma medida en que el espíritu y sus producciones [Produktionen] son superiores a la naturaleza y sus manifestaciones [Erscheinungen], descuella lo bello del arte por encima [höher] de la naturaleza. ${ }^{50}$

\author{
47. Ibidem, p. 129. \\ 48. Ibidem, p. 10. \\ 49. Ídem. \\ 50. Ídem.
}

Thémata. Revista de Filosofía N56 (2017) pp.: 13-40. 
Lo bello del arte no despunta del interior de la naturaleza sino por encima y es más alto (höher) en razón de su nacimiento espiritual, de la actividad transformadora del espíritu. No faltarán quienes, no carentes de razones fundadas, detecten una desnaturalización estética en Hegel. Pese a esto, la desnaturalización sería a todas luces momentánea y parcial ya que no se queda en una suerte de negación de la naturaleza sino que avanza hacia una complementación relacional para con la superioridad, siempre moviente y creativa, del espíritu. Esta superioridad, entonces, se puede sostener filosóficamente de dos maneras. En la primera de ellas, el alemán procede «bajo el aspecto formal» pues lo bello del arte, con mayor grado, «lleva el sello del espíritu y de la libertad» $»^{51}$, lo cual, en clara herencia de la kantiana Crítica del juicio (1790) ${ }^{52}$ para la cual no hay fines en la naturaleza, no lo encontramos en cualquier producto natural (Naturprodukt); que es ciego por sí solo. En la segunda manera, que atañe al contenido, cualquier objeto de la naturaleza por sí mismo es una existencia natural (Naturexistenz) que «no es libre en sí y consciente de sí; y si la consideramos en su conexión necesaria [Zusammenhange ihrer Notwendigkeit] con otras cosas, no la consideramos para sí misma, ni por tanto, como bella» ${ }^{53}$. Así las cosas, lo que logra una belleza superior, que es en la que se funda y la que estudia la estética, es la impronta libre y autoconsciente del espíritu. Pero esta actividad estética del espíritu no está apartada con respecto a la actividad y diversidad natural, sino que esta última es un darse parcial y efectivo de su despliegue total; el cual es inseparable e impensable tanto sin su habitarse consciente y libre absolutamente para sí mismo como sin su exteriorización natural.

El espíritu que se toma cuerpo en la cosas naturales no solamente es bello, es decir que place a la sensación, sino que también es verdadero, esto es, que consigue, inteligible y libremente, una plasmación material e incluye a las cosas naturales sólo en cuanto es sí-mismo. Como bien indica Hegel, «el espíritu es por primera vez lo verdadero [das Warhaftige], que lo abarca todo en sí, de modo que cualquier cosa bella sólo es auténticamente bella como partícipe [teilhaftig] de esto superior y engendrada por ello» ${ }^{54}$. El matiz de la participación o, más literalmente, del tener parte (teilha-

51. Ídem.

52. «Aducimos un fundamento teleológico allí donde atribuimos causalidad a un concepto del objeto con vistas a un objeto, como si dicho concepto se encontrara en la naturaleza (no en nosotros), o más bien nos representamos la posibilidad del objeto según la analogía con una causalidad tal (semejante a la que hallamos en nosotros)... si no le imputamos tal modo de actuar, su causalidad tendría que representarse como un ciego mecanismo», $K U \S 61 \mathrm{Ak}$. V, 360.

53. Hegel, G.W.F.: Lecciones, cit., p. 10.

54. Ídem.

Thémata. Revista de Filosofía №56 (2017) pp.: 13-40. 


\section{¿Disolución o reconciliación transformadora \\ de la estética en Hegel? Una respuesta}

ben), ya da una pista al investigador para comprender que aquello que participa de algo depende de aquello en lo que toma parte. Mas no estamos, de nuevo, ante la participación platónica, que participa desde la oposición griega del kosmos horatós y el kosmos noetós, sino de una participación al interior de la misma totalidad relacional de determinaciones engendrante. La naturaleza, en Hegel, es deficiente por sí sola para basar una estética racional. Pero, ¿cómo es la belleza de la naturaleza? Para el de Stuttgart, la belleza natural no llega a ser belleza libre y conscientemente dada por sí sola sino que «aparece [erscheint] solamente como un reflejo [Reflex] de lo bello perteneciente al espíritu, como una forma imperfecta, incompleta...

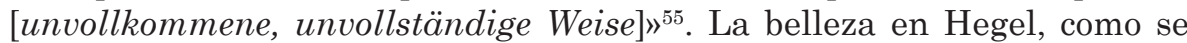
puede apreciar, no es obra de las cosas mismas: la naturaleza aisladamente no puede obrar su belleza, precisamente porque no puede ser desvinculada o arrancada del espíritu en el que adquiere unidad, haciéndola bella e inteligible. La naturaleza, pues, es deficiente sin el espíritu, único que la reconcilia consigo y la transforma realmente.

Así pues, no son los seres naturales quienes irradian por sí mismos la belleza porque no tienen en ellos dicho poder estético sino que, en ellos, la belleza brilla como apariencia (Erscheinung) y reflejo (Reflex) del espíritu, que es la substancia (Substanz) de la cual los productos naturales toman toda consistencia. En Hegel, lo bello no está substanciado en los seres de la naturaleza considerados en sí mismos solitariamente. Pero no hay que pensar esta relación espíritu-cosas naturales desde la mentalidad de la secesión dualista porque, en el filósofo, lo que cuenta es la totalidad, si bien es una totalidad extrovertida y dialéctica. Es una totalidad de determinaciones (Totalität von Bestimmungen), como ya apuntamos. El en-sí, sin ser transformado en el para-sí, no es más que apariencia. La belleza natural, pues, es figura incompleta, en la localidad cósica, del único despliegue del espíritu; el cual posee, como totalidad auto-consciente y libre, la belleza más perfecta. Hegel, aunque jamás renuncia a las cosas naturales, les priva de un espesor propio de belleza de forma aislada, el cual no es sino principalmente cualidad del para-sí supremo del espíritu, y, sólo secundariamente y por participación, de cualquier cosa en relación a él. Esto significa que el alemán no desnaturaliza la belleza completamente sino que es en la relación inseparable de la naturaleza con el devenir inteligiblemente más elaborado del espíritu, en su participación con él, mediante lo cual ésta vence su deficiencia y se vuelve bella.

No es que los seres naturales no sean bellos sino que simplemente jamás están al margen de su relación de belleza con el espíritu, la cual es

55. Ídem.

Thémata. Revista de Filosofía N56 (2017) pp.: 13-40. 
su modalidad ontológica fundamental ${ }^{56}$. El término «relación» (Beziehung), que hemos empleado mucho en este artículo en fidelidad al autor, aparece repetidas veces en Hegel. Básteme apuntar que, en el caso de los seres naturales entre los que se encuentra el mismo hombre, Hegel bautiza su relación con el espíritu, en la Einleitung de sus Leccciones de estética, como una "relación negativa [negativen Beziehung]» ${ }^{57}$. En el segundo capítulo, la vida natural [natürliche Lebendichkeit] «no tiene su ser inmediatamente en ella, sino que en su existencia está puesta a la vez negativamente» ${ }^{58}$. Pero la negación conduce a la afirmación puesto que la vida natural «no sólo tiene la relación negativa [negative Beziehung]» sino que «en la unidad ideal... recibe el poder de una relación afirmativa [affirmativer Beziehung] consigo» ${ }^{59}$ misma. La ontología hegeliana consta de una relación dual (no dualista) negativa-afirmativa. El ente está marcado por la negatividad y el ser-para-otro, lo cual lo mueve y es movido para ser afirmativamente en la idealidad del espíritu.

El ser del ente es inexplicable sin esta relación de alteridad (de la negación a la afirmación), como bien lo interpretó Herbert Marcuse en Hegel: «Como todo ente es sólo en el ser-otro, en la negatividad de sí mismo, tiene necesariamente que ponerse a prueba y afirmarse en la alteridad como aquello que él es» ${ }^{60}$. Pero esto no es una relación pasiva ya que lo que constituye ontológicamente a todo ente es una motilidad, que aunque negativa y escindida momentáneamente, es un conato del mismo ente hacia la alteridad que lo perfecciona no sólo en lo inteligible sino en lo estético. Marcuse advierte que «esta motilidad específica del auto-producirse, del mostrarse, constituye la «realidad» propia del ente: es esencialmente causarse, realizarse ${ }^{61}$. La ontología en Hegel, en base a la deficiencia y negatividad que le es propia al ente, es siempre una ontología de la relación también afirmativa en función de esta motilidad que ya pertenece a las cosas, esto es, una motilidad hacia lo bello por la que las cosas van siendo lo bello en su relación con el espíritu. ¿Habría -por añadidura a lo que

56. Resta saber dónde queda aquí la relación con el espíritu absoluto ya que la relación en Hegel es pensada en función de la negatividad natural, mientras que el espíritu es positividad. Esto oscurece, al menos para este análisis filosófico, la relación de ambos. Una legítima pregunta sería saber en qué medida el espíritu es trascendente en Hegel con respecto a la naturaleza, o si se trata más bien su pensamiento de una propuesta ontológicamente más procesual y no de una trascendencia entendida desde la escisión.

57. Ibídem, p. 38.

58. Ibídem, p. 111.

59. Ídem.

60. Marcuse, H.: Ontología de Hegel y teoría de la historicidad. Traducción de Manuel Sacristán. Barcelona: Ediciones Martínez Roca, 1970, p. 50.

61. Ídem.

Thémata. Revista de Filosofía №56 (2017) pp.: 13-40. 


\section{¿Disolución o reconciliación transformadora \\ de la estética en Hegel? Una respuesta}

apuntamos- una motilidad del espíritu en tanto que tiende a su alienación y positivización en la naturaleza finita? Sea como fuere, la naturaleza es motil y el espíritu absoluto es un espíritu inquieto y esencialmente impulsado a su exteriorización.

Por un lado, tenemos negatividad y por el otro positividad pero no como dos regiones separadas e inactivas sino en constante tensión dialéctica. Jiménez Redondo advierte que, aún pudiendo arribar esto a una interpretación atea, en el filósofo alemán, «Dios se hace hombre. [...], nada es sin ser lo otro de sí mismo, y lo absoluto no es sin ser lo absolutamente otro de sí, lo absoluto no es sin ser lo relativo, pues no es sino lo relativo como $\left.t_{a l}\right\rangle^{62}$. Este Dios cuya positividad se ve necesitada de la negatividad es distinta de una teología de la total trascendencia y de cierta ontología directa y positiva. En Hegel el hombre sólo puede ser y desarrollarse en Dios - ¿ser bello en su relación con él?- ya que, como comentaba el gran Alexandre Kojève, «la teología que distingue a Dios del hombre no es vernünftig (racional). Es necesariamente una mitología» ${ }^{63}$. Hegel no es, en efecto, un mitólogo de la escisión, sino un pensador relacional, un filósofo de principio a fin.

Sería oportuno que me preguntara si hay una ausencia absoluta de belleza ontológica en lo seres naturales en el filósofo de Stuttgart. Si interpretamos a Hegel desde una ontología fijista y realista clásica, ajena totalmente a su pensamiento, la respuesta sería absolutamente que no: los entes no son bellos considerados de manera aislada por la razón. No obsta decir que considerar algo de manera aislada por la razón es un sinsentido en Hegel: la razón es facultad de la unidad real, del todo dinámico. Si, por el contrario, adopto una ontología de la motilidad, que es la genuinamente hegeliana, me sería lícito afirmar que parcialmente sí hay belleza ontológica ya que, al menos, podría aducir que hay una semovencia ontológica hacia lo bello en las cosas en tanto en cuanto participan del espíritu embelleciente. Mas es exactamente en la relación con el espíritu, a la que tiende ontológicamente la motilidad de todo ente natural, en donde acontece la positivización y afirmación de lo bello. Schallum Pierre indica con acierto que «según Hegel, lo bello no se desprende de la imitación de la naturaleza

62. Jiménez Redondo, M.: "Prólogo" en Kojève, A. Introducción a la lectura de Hegel. Traducción y glosario de Andrés Alonso Martos. Madrid: Editorial Trotta, 2013, p. 17.

63. Kojève, A. Introducción a la lectura de Hegel. Traducción y glosario de Andrés Alonso Martos. Madrid: Editorial Trotta, 2013, p. 88.

Thémata. Revista de Filosofía No56 (2017) pp.: 13-40. 
(Nachahmung der Natur) sino de la presentación o manifestación (Darstellung, Schein, Erscheinung) del espíritu (Geist) en el arte» ${ }^{64}$.

Habida cuenta de esto, Hegel creyó que había que prosperar de la ontología y filosofía de la naturaleza a la estética, entendida como filosofía del arte bello, para estudiar de manera científica -y más completa- lo bello. ¿Se disuelve la ciencia estética en el arte? La clave para responder a este interrogante la encontraremos en el espíritu creador del arte que obra lo bello artístico, como veremos en el próximo punto.

\section{Lo bello artístico: la clave de la transformación de la estética}

Para quienes creen que, en el pensamiento de Hegel, se liquida la estética en el arte, le recomendaría que leyese con más detenimiento a este autor. Incluso en la Einleitung de sus Lecciones de estética, la consideración del arte se desprende primeramente de la consideración científica y racional puesto que «en tanto iniciamos el tratado científico [wissenschaftlich] del mismo, hemos de comenzar por su concepto [Begriff]» ${ }^{65}$. Lo que se está buscando es fundamentar una ciencia estética, y, para ello, lo más imperioso es el rigor conceptual. Y es que «una vez hayamos fijado este concepto, podremos exponer la división y con ello el plan total ${ }^{66}$ de la ciencia estética. Los que opinan que el alemán ha trastocado la estética en una mera consideración del arte no tienen en cuenta la voluntad de Hegel de que esto «no ha de hacerse en forma meramente extrínseca [äußerliche Weise], como sucede fuera de la filosofía» ${ }^{67}$. El arte, como ineludible para la única ciencia estética, "debe encontrar su principio en el concepto mismo del objeto» ${ }^{68}$ y no, como se ha dicho hasta la saciedad, disolverse en él. La estética hegeliana "propone un movimiento histórico -la progresión y la particularización del Espíritu en tres formas artísticas - es decir, arte simbólico, arte clásico y arte romántico $\rightarrow{ }^{69}$. Si en algo el arte moriría no sería sino en estas formas artísticas. En el caso del arte clásico, éste se disuelve al perder el hombre su simbiosis con la physis, pero en el romántico

64. Pierre, S.: "Hegel, l'art et le problème de la manifestation : l'esthétique en question" en Phares 11, (3), 2011, p. 27.

65. Hegel, G.W.F.: Lecciones, cit., p. 27.

66. Ídem.

67. Ídem.

68. Ídem.

69. Holzermayr Rosenfield, R.: op. cit., p. 1.

Thémata. Revista de Filosofía $\mathrm{N}^{\circ} 56$ (2017) pp.: 13-40. 
también, porque la subjetividad no sería convenientemente satisfecha con su embriaguez creadora, intimista y prosaica. El arte romántico muere porque no sería más que autoafirmación pseudo-religiosa y pseudo-filosófica en el yo ebrio de sí que en verdad está vocacionado a conceptuar el absoluto. El artista, para ser artista, también ha de ser filósofo, lo cual es un precio desorbitante que los partidarios de la muerte del arte no están dispuestos a pagar. No hay artista ni arte ni obra si no hay simultáneamente concepto.

Sin embargo, en Hegel el concepto no se reduce a simples suposiciones (Annahme) o presupuestos (Voraussetzung) arbitrarios pues «lo que ha de valer para él deber ser mostrado en su verdad [Wahrheit], es decir, mostrarse como necesario [notwendig]» ${ }^{70}$. Como es propio de la ciencia y no de la contingencia y variedad de las obras de arte, la estética en su conjunto se esmera por elucidar su verdad y necesidad; lo cual lleva a afirmar la muerte del arte en cuanto arte. Pero esta verdad y necesidad no es como la ceguera natural, sino que corresponde al dinamismo creativo del espíritu. Hegel, jamás hubiese querido el fin del arte, sino su plenificación racional. Lo que para gran parte de la crítica sería muerte para mí, si lo que pretendo enseñar la estética del alemán, es un crepúsculo del arte si es tomado $a$ solo. La importancia indiscutible que Hegel otorga al arte no resta una mayor relevancia a una estética que lo comprende desde la perspectiva científica, es decir, desde la universalidad, necesidad y verdad del espíritu. En el filósofo, el arte se ocupa de la mostración (weisen) de lo bello, mientras que la estética en su conjunto, como filosofía del arte bello, se centra en su demostración: «En estas ciencias, que versan sobre lo dado sensiblemente, los objetos son tomados de la experiencia exterior, y, en lugar de demostrarlos [beweisen], se considera que es suficiente mostrarlos [weisen] ${ }^{71}$. No basta con hacer sensible lo bello: lo que aparece exteriormente, a menudo cambiante e inconsistente, ha de tener un soporte conceptual más relevante que el simple agrado y sentido esporádico del sujeto:

Por ejemplo, con frecuencia lo bello ha sido considerado como algo que no aparece con necesidad en la representación según su condición «en sí y para sí» [an und für sich], sino que tan sólo se encarna en ella como un mero agrado subjetivo [subjektives Gefallen], como un sentido meramente casual [zufälliger Sinn $]^{72}$.

70. Ídem.

71. Ídem.

72. Ibidem, p. 28.

Thémata. Revista de Filosofía №56 (2017) pp.: 13-40. 
En Hegel, lo bello del arte no interesa a su disciplina como algo azaroso y a merced de los gustos del sujeto, esto es, como algo que dependa de cada sensibilidad artística y cambie, de este modo, su verdad según quien lo aprecie. En esto, el filósofo se opone a una suerte de relativismo estético que, en congruencia con el racionalismo que hemos resaltado anteriormente, le conmina a buscar los fundamentos científicos de lo bello del arte. Más bien, lo bello «es un resultado de algo precedente, lo cual, considerado según su verdadero concepto, conduce con necesidad científica [wissenschaftlicher Notwendigkeit] al concepto de arte bello» ${ }^{73}$. La estética hegeliana no estudia lo bello como fruto, por un lado, de facultades naturales particulares tales como el agrado ni, por otro lado, de objetos particulares como las obras de arte. La experiencia de lo bello y su plasmación material conciernen mutuamente a Hegel sin prescindir del rigor conceptual, el cual es el que justamente prepara la deseada reconciliación transformadora. La estética del alemán no se escinde, pues, en una teoría del sujeto y en una teoría del objeto enfrentados. En otras palabras: el de Stuttgart persiguió reconciliar el polo subjetivo y el polo objetivo de la belleza estética desde la acción transformadora del espíritu que conceptualiza.

El arte, considerado por sí solo, nada sabe del concepto de lo bello en sí y para sí sino que lo toma como «un presupuesto [Voraussetzung] que cae fuera de nuestra consideración» ${ }^{74}$. Por ello, «no queda otro camino que el de asumir el concepto de arte a manera de lema [lemmatisch]» ${ }^{75}$. Lo bello en su esencial es depuesto por el arte, lo cual es el reto que Hegel se propuso encarar y revertir. En el arte, entonces, se sabe mucho de las configuraciones particulares de lo bello y de las técnicas para su creación pero, de mientras, lo bello es conceptualmente tenido como ya dado, como un lema en el cual todavía no se ha ahondado y en el que incluso sería prescindible tal profundización racional universal. Hay, por el contrario, que transformar lo bello lemático del arte en lo bello científico de la estética, lo particular en lo universal sin que se pierdan ambos. La filosofía -he mostrado que la estética es a todas luces filosófica en Hegel- es la forma más alta de ciencia puesto que «solamente la filosofía en su conjunto es el conocimiento del universo [Erkenntnis des Universums] como una totalidad orgánica [organische Totalität], en sí mismo» ${ }^{76}$. A la estética hegeliana le preocupa, pues, lo bello artístico en tanto en cuanto lo estudia desde la

\footnotetext{
73. Ídem.

74. Ídem.

75. Ídem.

76. Ídem.
}

Thémata. Revista de Filosofía №56 (2017) pp.: 13-40. 


\section{¿Disolución o reconciliación transformadora \\ de la estética en Hegel? Una respuesta}

óptica totalizante del espíritu, a partir de una totalidad que, al ser orgánica, incluye lo particular sin suprimirlo. Una cosa es la experiencia de lo bello y sus expresiones artísticas, y otra -todavía más decisiva y complementaria como su base- es la ciencia de lo bello artístico.

Lo primero es el espíritu en Hegel pero también lo último, si bien hay fases intermedias que comprenden lo particular en el mismo dinamismo espiritual. La totalidad que conoce en sí la filosofía "se desarrolla desde su propio concepto y, a través de una necesidad que se comporta consigo mismo, vuelve al todo en sí, se cierra en conjunción consigo como un mundo de la verdad [eine Welt der Wahrheit» ${ }^{77}$. Esta totalidad es comparada por el alemán a un círculo (Kreis) en el que no hay vacíos, ni tampoco otro circulo material-particular paralelo. Si esto fuera así, habría dos mundos de la verdad (un mundo sensible y un mundo inteligible), mientras que Hegel sólo habla de uno en constante transformación dialéctica. No hay un mundo del arte y otro de la estética. Tampoco uno se sitúa ante un círculo vicioso ya que esta totalidad «es un círculo que vuelve hacia sí y, por otro lado, guarda una relación necesaria con otros ámbitos», estando provista históricamente de «un detrás [ein Rückwärts] de donde se deriva y un delante [ein Vorwärts] hacia donde sigue avanzando» ${ }^{78}$. Así las cosas, la estética hegeliana no disuelve una cosa en la otra sino que apunta hacia la reconciliación Rückwärts-Vorwärts, siempre en el horizonte transformador del espíritu "por cuanto engendra fértilmente otra cosa desde sí» ${ }^{79}$. La motilidad ontológica de las cosas es posible en tanto en cuanto el espíritu concibe y llama a las cosas a formas cada vez más perfectas de belleza. Es una motilidad de belleza que aumenta cualitativamente con la obra de arte, en la cual el espíritu humano rescata la materia de sus grados cualitativos inferiores y la transforma en bella.

En el capítulo tercero de las Lecciones, dedicado a lo bello artístico como ideal, observamos cómo el espíritu le da a esa materia una infinitud que ella no tiene: el objeto material, que el artista usa para crear belleza, es denominado por Hegel "existencia finita [endlichen Dasein]», haciendo falta «la elevación a la autonomía y libertad absoluta [die Erhebung in die unendliche Selbständigkeit und Freiheit] ${ }^{80}$ de la que carece su finitud. En el arte se produce, entonces, un acto creativo elevador de la materia por parte del artista ya que "sólo la animación [Beseelung] y la vida [Leben] del espíritu es la infinitud libre [freie Undendlichkeit], que en la existencia real es para sí misma como interior, porque en su manifestación retorna a

77. Ídem.

78. Ídem.

79. Ídem.

80. Ibídem, p. 140 .

Thémata. Revista de Filosofía Nº56 (2017) pp.: 13-40. 
sí misma y permanece en sí» ${ }^{81}$. Hegel se opone al solipsismo en su estética ya que, para que pueda darse belleza artística -y para que así se considere- la idea de lo bello que el artista posee ha de salir de la soledad pensante para plasmarse en la obra material y retornar luego a sí.

No hay belleza sin obra: la experiencia estética no es una experiencia simplemente racional sino también material. No es suficiente con preguntarle al artista por qué su extraña obra es bella, como a veces sucede en algunas perplejizantes obras contemporáneas, sino que en lo obrado mismo, en su materia, debe despuntar lo bello. Si falla la obra, no estamos ante la estética de Hegel. Si no hay idea, tampoco es Hegel. En el arte hegeliano, se anima, se infinitiza, se positiviza y se vivifica a la materia de la obra a través del genio creativo y las determinadas técnicas con las que cuenta el artista. Por esto mismo, no erramos si afirmamos que el arte tiene un plus de reconciliación y transformación que la sola ontología y la sola filosofía de la naturaleza carecen (aunque no sean pasivas del todo), como tampoco hallamos esto en cualesquiera de las disciplinas de la exterioridad; de modo que, con el fin de darles una mayor profundidad espiritual, Hegel puede introducir su propia estética. La estética del de Stuttgart amista sin unilateralidades lo bello natural y loa bello artístico, aunque obviamente este último es cualitativamente mejor porque está más consumado.

La estética del alemán no es la menesterosa descripción y taxonomización de los rasgos agradables de la obra de arte sino que, en su finalidad transformadora, entiende que «el arte tiene la destinación [Bestimmung] de captar y representar la existencia en su aparición como verdadera, o sea, en su adecuación [Angemessenheit] con el contenido adecuado a sí mismo, con el contenido que es en sí y para sí» ${ }^{82}$. El espíritu es quien destina la verdad y belleza de toda obra natural, y, en lugar de adecuar las cosas desde la separación - pues «la verdad del arte no puede ser una mera corrección» ${ }^{83}$ - más bien el espíritu — siendo fieles a la lengua alemana- las hace idóneas y razonables (angemessen) con la idea de lo bello. Sin esta verdad idónea con el creador concipiente, que Hegel llega incluso a extender a toda la naturaleza en relación a Dios ${ }^{84}$-del que es análogo el hombre-, la belleza natural u artefactual no sería más que espejismo

81. Ídem.

82. Ibidem, p. 141.

83. Ídem.

84. «La naturaleza y sus productos, se dice, son una obra de Dios (Werk Gottes), han sido creados por su bondad y sabiduría, mientras que el producto artístico es solamente una obra humana (Menschenwerk), hecho por manos de hombre y según el conocimiento humano... En esta contraposición... late la idea errónea de que Dios no opera en el hombre y por el hombre, sino que el círculo de esta actividad se reduce a la naturaleza», Ibidem, p. 33. 
ilusorio y sin fundamentación. Nada de la apariencia sensible de una obra de arte tiene sentido ni consistencia sin la verdad de su obrador, si bien él necesita igualmente -tanto para que pueda haber arte como experiencia de lo bello- sensibilizar su eidos, sacarlo de sí y materializarlo.

Con el Schelling de un único absoluto pero en tajante distanciamiento de su defensa de lo bello natural como superior, en Hegel lo bello artístico combina, en la misma espiral dialéctica del espíritu, la exterioridad y la interioridad; eximiéndonos de paradojas dualistas que nos constriñan a elegir entre dos estéticas, o a cambiar una por otra: una del arte y otra del genio creativo. En Hegel, lo bello artístico es superior ya que goza de la belleza más elaborada en comparación con Schelling: es la dotación a lo natural deficiente -pero motil- de la espiritualidad creativa. Muchos esgrimen, no sin motivos fundados, que el arte muere en Hege ${ }^{85}$ porque el en-sí material, sin el espíritu, no puede considerarse vivaz; pero hemos de insistir en que su pensamiento es dialéctico y no -como en Schelling- la absolutación de la naturaleza como única fuerza productiva (Leibskraft). En-sí y para-sí son inseparables en el alemán en la misma ciencia procesual y dinámica de lo bello. Solamente hay una estética en Hegel en la que tanto lo finito como lo infinito se complementan dialécticamente en la consideración total, pero no homogénea, del mismo espíritu, ya que "lo exterior ha de concordar [zusammenstimmen] con un interior, que es concordante en sí mismo, y, por ello, puede revelarse [offenbaren] como él mismo en lo exterior» ${ }^{86}$. Cuando se revela en lo exterior, el espíritu no deja de ser él mismo sino que es más sí mismo. En el arte, entonces, el obrador selecciona entre la materia lo mejor para revelar su idea, de modo que al mismo tiempo liberta su idea del interior pensante y a la materia de aquello que en ella no es idóneo con lo bello:

Así, pues, en tanto el arte hace retornar a la armonía [Harmonie] con su verdadero concepto lo que en el resto de lo existente está mancillado con la causalidad y exterioridad, deja de lado todo lo que en la aparición no corresponde a aquél, y mediante esta purificación [Reinigung] produce el ideal ${ }^{87}$.

Como uno acaba de leer, lo bello artístico es lo idealmente armónico, en comparación con lo casual y exterior de lo naturalmente-todavía-no embellecido por el espíritu. La estética de Hegel que, con el fin de escapar-

85. Cfr. Ballén Rodríguez, J.S.: "Sobre la muerte del arte en las Lecciones de Estética de Hegel" en Universitas Philosophica 59, (29), 2012, pp. 179-194.

86. Ibidem, p. 141.

87. Ídem.

Thémata. Revista de Filosofía N56 (2017) pp.: 13-40. 
se de un vano solipsismo espiritualista así como de un esteticismo, une sin fusiones ni fisiones el espíritu y al arte; siendo una estética dinámica de la armonía (Harmonie) y la purificación (Reinigung). Por un lado, la estética es armónica porque el sujeto y el objeto se necesitan mutuamente en la creación de lo bello. Además, la estética purifica la materia, toda vez que la necesita; porque implícitamente está queriendo indicar el alemán que en la materia se halla algo potencialmente idóneo con lo bello. Lo bello no es una extravagante invención abstracta: se concretiza sin perder su eidos, es decir, «se queda en el punto medio [Mittelpunkte], en el que coinciden lo meramente exterior y lo meramente interior» ${ }^{88}$. Apostando, en efecto, por una reconciliación transformadora, la estética de Hegel se encuentra a mitad del abstraccionismo y el concrecionismo, del internismo y el externismo.

Corresponderá, pues, al artista acometer esta armonía y purificación, si bien no en obediencia a su capricho sino a la verdad y universalidad del espíritu absoluto, que no sólo tiene en tanto que subjetivo sino que en él se conciencializa y opera en tanto que absoluto puesto que «no sólo hay algo de divino [Göttliches] en el hombre, sino que lo divino actúa en él de una manera totalmente superior [hörerer], más adecuada a la esencia de Dios que la acción de la naturaleza ${ }^{89}$. El hombre es capaz de crear lo bello en el arte y, mientras más procede Dios en él, lo es también de lo sublime (Erhabenheit), en lo cual hay absoluta libertad e incondicionalidad ${ }^{90}$. No tiene razón el marxista Bloch al insistir en que «la Estética de Hegel no es devota $»^{91}$, aunque -la sinceridad me obliga- es una devoción muy poco numinosa. El arte, como afirma Bayer, "gracias a su libertad, es -según Hegel- algo muy distinto y cumple exactamente la misma misión que la religión y la filosofía: es un modo de expresar lo divino y de hacer sensible el espíritu absoluto» ${ }^{92}$.

\subsection{Dificultades}

Lo que he podido escribir hasta el momento no me impide destacar las dificultades en la articulación de lo bello natural y lo bello artístico. ¿Qué enlace existe entre lo bello natural y lo bello artístico? En el tercero de los cuatro cursos de Estética impartidos en la ciudad de Berlín en 1826,

88. Ibídem, p. 142.

89. Ibidem, p. 33.

90. Cf. Ibídem, p. 337.

91. Bloch, E.: op. cit., p. 259.

92. Bayer, R.: op. cit., p. 319.

Thémata. Revista de Filosofía $\mathrm{N}^{\circ} 56$ (2017) pp.: 13-40. 
recogidos directamente por Von Kehler, en comparación con el rasgo más indirecto de los apuntes de Gustav Hotho y Von Ascheberg, observamos que en «la tesis fundamental de la estética filosófica de Hegel, el arte cumple de modo pleno sus posibilidades cuando proporciona al hombre una autoconciencia histórica, es decir, cuando da respuesta a su necesidad de sentido y orientación ${ }^{93}$. Pero este propósito no siempre es fácil y está plagado de dificultades. Las notas de Von Kehler me vienen francamente bien para articular la relación entre lo bello natural y lo bello artístico. He aquí la mayor de las dificultades a vencer.

Si lo bello artístico es superior a lo natural, entonces puedo preguntarme en qué consiste su superioridad. En este otro Hegel, «puede decirse que la superioridad de lo bello artístico sobre lo bello natural es proporcional a la del espíritu sobre la naturaleza ${ }^{94}$. Incluso, en esta supremacía espiritual humana, el de Stuttgart osa afirmar que "lo peor que a uno pueda ocurrírsele es cosa mejor que la naturaleza", todo lo contrario de un Schelling absolutizador de la misma ${ }^{95}$. Esto bien pudiera parecer una desconexión del acto creativo con su materia pero no hay que precipitarse en afirmar esto. Para Hegel, el significado de superior no es «sólo algo cuantitativo ${ }^{96}$ sino principalmente cualitativo en el espíritu humano. Mientras que «lo bello natural es un reflejo del espíritu, en cuento modo incompleto de lo espiritual», no debemos pensar esto de desde la lógica de la separación dualista ya que los bello natural sigue siendo «un modo que ya está contenido en el espíritu, aunque sólo es un modo no autónomo en él $»^{97}$. No podemos pensar la estética, en concordancia con la ciencia de Hegel, desde una autonomía total, según una suerte de fractura ontológica como la platónica. Se trataría de una autonomía heterónoma, permítaseme el oxímoron, que expresa mejor la ontología relacional hegeliana.

En efecto, «lo bello es bello artístico por el espíritu, y lo bello natural puede conservar su nombre sólo en relación con lo espiritual» ${ }^{98}$. Se han de pensar las cosas como confrontadas irremisiblemente ya que -y aquí aportamos un cita importantísima del filósofo alemán- «ha de establecerse una relación completamente distinta a la relación de yuxtaposición» ${ }^{99}$, lo

93. Berr, K. y Gethmann-Siefert, A.: "Prólogo. -Sobre los apuntes de Kehler" en Hegel, G.W.F.: Filosofía del arte o Estética. Apuntes de Friedrich Carl Hermann Victor von Kehler. Madrid: Abada Editores / Universidad Autónoma de Madrid Ediciones, 2006, p. 17.

94. Hegel, G.W.F.: Filosofía del arte o Estética, cit., p. 49.

95. Ídem.

96. Ídem.

97. Ídem.

98. Ibídem, p. 50.

99. Ídem. 
cual refuerza nuestra tesis de que la estética de Hegel es reconciliadora y para nada reductora, o, in extremis, disolutiva. En 1826, el de Stuttgart enseñaba una suerte de pulchrum pero no como trascendental clásico sino inmanente en lo más concreto: "La belleza en general se inmiscuye en cada una de nuestras circunstancias; es el genio amistoso que nos sale al encuentro por todos lados» ${ }^{100}$. Esta «belleza en general» no es la idea platónica -ontológicamente aislada y en una misteriosa participación- sino que es radicalmente inmanente en la presencia del nivel cualitativo en lo cuantitativo de la naturaleza y de las obras de arte materialiter considerata. Lo cualitativo y lo cuantitativo se necesitan recíprocamente en Hegel.

De manera más explícita que las Lecciones de Estética de Hotho y Von Ascheberg, el arte no es, en el pensador germánico, una traición a la estética, ni una disolución de la misma: «El arte es simplemente una forma en la que el espíritu se lleva a aparición fenoménica; es un modo particular [de su aparición fenoménica]» ${ }^{101}$. Hegel es aún más rotundo al tratar al arte como «modo particular, el espiritual llevar-se-a-aparición-fenoménica, debe ser esencialmente resultado» ${ }^{102}$ del espíritu. Con la mentada expresión no se puede plasmar textualmente mejor nuestra interpretación de Hegel: arte no es técnica eficiente ni rareza erudita sino el «llevar-se-a-aparición-fenoménica» del solo espíritu que atraviesa y preside toda la naturaleza y se conciencializa en un hombre que puede crear obras bellas.

Por ello, uno se tiene que oponer a que lo bello sea excluido de la filosofía para hacerlo algo totalmente sentimentalista porque con ello "se quiere huir del concepto, del pensamiento» ${ }^{103}$. Antes de ponerme a filosofar profesionalmente, el concepto ya empezaba a exteriorizarse, esto es, pensamiento y materia se desenvolvían en la espiral dialéctica. La obra de arte no es un agregado del concepto sino que, por el contrario, deviene concepto obrado. Sin temor a equívocos, «el concepto es la determinación inmanentemente propia» ${ }^{104}$ y no un arquetipo fuera de la naturaleza: se inmanentiza espiritualmente a cada quien.

En discordancia con lo que acabamos de indicar, lo que ha dominado el pensamiento clásico es la oposición de pensamiento y materia. Habida cuenta de esto tendremos que vencer «esta oposición como una dualidad de mundos» ${ }^{105}$, que el hombre vive dramáticamente entre su inteligencia y la limitación de sus inclinaciones pasionales puesto que, de lo contrario,

100. Ídem.

101. Ibidem, p. 53.

102. Ídem.

103. Ibidem, p. 61.

104. Ibidem, p. 121.

105. Ibidem, p. 77. 
en «esta oposición se halla el espíritu y anda dando tumbos en la contradicción de tal oposición» ${ }^{106}$. Dicha oposición ha de ser reconciliada ya que, en el mismo hombre, el espíritu no se manifiesta sin la corporalidad que le es inherente: «lo espiritual también debe aparecer en lo corporal [...] el aparecer del espíritu se da en la figura humana ${ }^{107}$. Incluso Dios no se puede desarraigar del hombre: «el espíritu divino mismo, si tiene que permanecer en el arte, debe aparecer en figura humana ${ }^{108}$. La estética, en lo que concierne a su disciplinariedad, adopta la reconciliación como su punto de partida y su punto de llegada, con tal de resolver la perspectiva opositora y contradictoria:

Concebida totalmente en su profundidad, ésta es la perspectiva de la contradicción no resuelta en general; por encima de esta perspectiva hay que poner la de la oposición que se resuelve, que se reconcilia; y ello es, aquí, la afirmación de que el fin último del arte es exponer el fin último absoluto. Lo supremo, la idea de la oposición que se reconcilia, es la perspectiva en la que se encuentra el arte $[\ldots]^{109}$.

La oposición a reconciliar es lo que se propone la estética gracias a un fin del arte que pueda darse efectivamente y no como mera idea, en contra de como sucedía en Kant. Para Hegel, «la filosofía kantiana ha indicado respecto a lo bello la abstracta disolución de la oposición; pero únicamente en el sentido de que sea un modo subjetivo nuestro» ${ }^{110}$. Lo bello no es un a priori sino que viene ofrendado a la conciencia humana y sale de ella en el auto-despliegue inescindiblemente subjetivo-objetivo del mismo espíritu absoluto. El arte es ya este espíritu que se conciencializa para sí de manera primeramente absoluta, esto es, asumiendo -pero no consumiendo- la naturaleza y las materias primas de la obras a crear.

\section{Conclusiones: ¿Disolución o transformación de la estética?}

Creo lisamente que he dado algunas pistas al interrogante que encabeza este punto final. Y es que, con el fin de concluir y responder muy brevemente a la pregunta de todo este estudio - si la estética se disuelve o se transforma en Hegel- tendremos que acudir sin demora a interrogar a nuestro pensador sobre el fin del arte bello. ¿Cuál es, pues, la finalidad del arte que concretiza la

106. Ídem.

107. Ibídem, p. 123.

108. Ídem.

109. Ibidem, p. 79 .

110. Ibidem, p. 81. 
ciencia estética de Hegel? Cuando a lo largo de este artículo he defendido que el alemán, a imitación de su política, entiende la estética como reconciliadora no estaba traicionándolo. De hecho he hallado literalmente esta expresión en el filósofo al responder a la pregunta acerca de la finalidad del arte:

«Hay que afirmar [...] que el arte está llamado a descubrir la verdad bajo la forma de la configuración artística, a representar dicha oposición como reconciliada [versöhnten], con lo cual tiene su fin último en sí mismo, en esta representación y en este descubrimiento» ${ }^{111}$.

La estética de Hegel se distingue de una filosofía pura entendida como baldía de plasmación material porque no solamente estudia la verdad extra causas sino, específicamente, lo bello. Mas la estética hegeliana no abjura de la verdad para complacerse con la sensación de lo bello o las determinaciones del arte sino que, como hemos visto en este artículo, persigue reconciliar (versöhnen) en lo bello la presunta oposición idea vs. materia, y, con más calado universal, la pugna filosofía vs. arte. El arte se ocupa de la primera oposición y la estética tanto de la primera como de la segunda, ya que integra en su tarea conceptualizadora al arte pero también no duda en fundamentarlo racionalmente. Puesto que la estética es ciencia y toda ciencia es filosófica, la estética del alemán "aporta solamente la penetración en la esencia de la oposición, en tanto muestra que, lo que es verdad, no es otra cosa que la disolución [Auflösung] de aquélla, por el hecho de que no son en verdad la oposición y sus aspectos, sino que éstos son verdaderamente en la reconciliación [Versöhnung]» ${ }^{112}$. En vez de que la estética se disuelva en Hegel, lo que apreciamos es lo contrario: sobre todo lo que es disuelto es la falsa oposición filosofía vs. arte, y, en lugar de quedarse en la disolución de ambas, avanza hacia la reconciliación. La filosofía entra en el arte y el arte en la filosofía.

¿Qué ocurre con la tan sonada idea - sin duda no carente de razón- de la muerte del arte? Advierte Rebok que «Hegel no emplea nunca la expresión "muerte del arte" ${ }^{113}$, por lo que seguramente se ha hablado de más sobre de esto, cuando, haciendo honor al sistema hegeliano, la religión y la filosofía no matan pretenden acabar con el arte sino que le imprimen -o incluso reconocen- más espesor espiritual en su tarea. De hecho -insiste Rebok- «el arte tiene su después en la filosofía como tuvo su antes en la naturaleza» ${ }^{114}$. Quizá, más que de «muerte», sería mejor hablar de «crepúsculo» del arte porque, sin la filosofía, éste se obscurece y se devalúa en una calística. Por ello, y en el léxico hegeliano, no muere estrictamente el arte en la filosofía ni la filosofía en

111. Hegel, G.W.F.: Lecciones, cit., p. 337.

112. Ídem.

113. Rebok, M.G.: “¿Muerte del arte o estetización de la cultura?” en Tópicos. Revista de Filosofía de Santa Fe 15, 2007, p. 56.

114. Ibidem, p. 240. 
el arte. Más bien, la filosofía revive en el arte y el arte en la filosofía, si bien esto no obsta que, a tenor de posturas vitalistas, irracionalistas, materialistas, o simplemente que no compartan la ontología de la motilidad hegeliana, la propuesta de llevar a concepto universal el arte supondría irreparablemente matarlo en cuanto tal.

Pero Hegel no lo vería con la misma mirada: no es que el arte muera o se acabe sino que es estetizado filosóficamente, y, si esto se considera un ensombrecimiento a ojos de los críticos, es porque el arte deja de ser mera producción de cosas o imitación directa de la naturaleza para devenir el fruto hacendoso de lo que es querido y pensado por el espíritu, gracias a y no pese a la materialidad de lo obrado. Hegel jamás asentiría a que se le imputase que estetizar el arte es matarlo. Quizá desde otra estética de la autonomía del arte -sin duda legítima- se puede abogar por esto pero ya no será la de Hegel. Quiero añadir a esto, no sin ironía, que obviamente uno debe ser demasiado hegeliano para no achacar a Hegel la muerte del arte, lo cual no despoja de razón a quienes sostienen cabalmente esta tesis. Sin embargo, según el de Stuttgart, la estetización del arte es un llamada a una mayor qualitas intelectiva del mismo -una transformación-, afectando en continuidad a su condición cuantitativa. Como leemos en Éric Guay, «el arte es la primera manera por la cual el espíritu finito llega a superar efectivamente sus limitaciones naturales» ${ }^{115}$, pero superar, en la estética de Hegel, no es negar sino que es liberar lo concreto para la belleza. Así lo confirma François Châtelet en Hegel según Hegel, si uno desea volver a la tercera parte de las Lecciones:

La estética: 'Una tarea que es, a nuestro parecer, una de las más importantes de todas las que se ofrecen a la Ciencia. En el Arte, en efecto, no se trata de un simple juego útil o agradable, sino de una liberación del espíritu del contenido y de la forma de la finitud: se trata de la presencia de lo Absoluto en lo sensible y lo real, de su conciliación con uno y otro, del completo desarrollo de la verdad, cuya esencia no agota la historia natural, sino que se manifiesta en la historia universal, donde podemos hallar la más bella y alta recompensa a las duras tareas de lo real y los penosos esfuerzos por conocer"116.

Quizá en la estética de Hegel se pueda hallar, en lugar de muerte, una "sublimidad del arte»" ${ }^{117}$, que -soy consciente de ello- no puede ser profesada si se considera de entrada errado su sistema filosófico totalizador. En efecto, puedo afirmar sin temor a equivocarme que, así como en el arte su finalidad

115. Guay, É.: La Phénoménologie de l'Esprit de Hegel et l'esthétique de maturité. Quebec: Université du Québec à Trois Rivières, p. 239.

116. Châtelet, F.: Hegel según Hegel. Barcelona: Editorial Laia, 1973, p. 177.

117. Gody Martínez, M ${ }^{a}$.J.: “¿Muerte o sublimidad del arte?” en $\Delta a \imath \mu \omega v$. Revista Internacional de Filosofía 57, 2012, p. 151. 
es vencer la oposición idea/materia y reconciliarlas, la estética, que incluye el arte pero que lo supera dándole sentido universal, tiene como finalidad la reconciliación arte-filosofía teniendo como objeto, como hemos visto, tanto lo bello natural -deficiente- como lo bello artístico -superior-. Esto es ya una especificidad que consigue que la estética de Hegel no pierda su propio estatuto epistemológico con respecto a otras disciplinas, como la lógica, la ontología o la filosofía de la naturaleza. El pensador, como hemos comprobado a través del arte, ha querido vencer un esteticismo - de la sensación de lo bello por la sensación- y un conceptualismo - de la idea por la idea-; aunque también una calística de un arte autónomo que reclamaría una estética reducida a su materialidad. No he hallado esto en el filósofo, ni tampoco el idealismo absoluto de Fichte, sino que he preferido mostrar que Hegel está más del lado de la unidad de Schelling, pero preponderando, como nunca antes, la reconciliación del espíritu absoluto con la materia en el arte. Hegel, aunque no faltan quienes discuten si conquistó esto, buscó adrede la dicha reconciliación -y no la muerte o la disolución- del arte y la filosofía. Mi intención no ha sido, en efecto, corregir a Hegel sino esculpir los fundamentos de su estética y estudiar sus propias razones al respecto.

También, y como colofón, he abogado por la transformación en Hegel: ¿Usa literalmente el alemán este concepto en su estética? La respuesta es que sí: como expresión, en este caso de la literatura, del paso de formas artísticas menos perfectas a otras mejores, tanto en lírica como en prosa, en orden a lo bello: ya que «de cara a tal transformación [Umwandlung], las artes particulares reciben una posición muy variada... la substancia interna de lo representado permanece la misma, pero la formación desarrollada hace necesaria una transformación [Umwandlung] en lo relativo a la expresión y la forma» ${ }^{118}$. En suma, reconciliación (Versöhnung) y transformación (Umwandlung) es lo que jalona e identifica la estética de Hegel, y de ningún modo la disolución (Auflösung).

118. Ibídem, p. 240 y p. 241 respectivamente. 